\title{
РЕЦЕНЗИИ, БИБЛИОГРАФИЯ
}

С. П. Карпов

DOI: $10.7256 / 2222-1972.2013 .5 .9553$

При иитировании этой статьи сноска на доі обязательна

\section{Новые горизонты медиевистики: от Италии до Золотой Орды}

\begin{abstract}
Аннотачия: в статье рассматриваются несколько исследований последних лет, пониманием вопроса и научной методологией опередившие время и определившие вектор дальнейшего развития некоторых направлений в исторической науке: Крамаровский М.Г. Человек средневековой улииы. Золотая Орда. Византия. Италия. СПб., 2012; От Онона к Темзе. Чингисиды и их западные соседи. К 70-летию Марка Григорьевича Крамаровского. М., 2013; Пономарев А.Л. Эволюиия денежных систем Причерноморья и Балкан в XIII-XV вв. М., 2011. В этих работах мы имеем дело с научными открытиями на стыке нескольких дисииплин.
\end{abstract}

Annotation: This article examines several investigations of recent years that were ahead of their time for understanding the question and a scholarly methodology and vector for further development of certain directions in the history of science: Kramarovskii, M. G. Man of the Medieval Street. The Golden Horde. Byzantine, Italy. St. Petersburg, 2012; From the Onon to the Thames. Chingizids and Their Western Neighbors. On the 70th Year of Mark Grigorevich Kramarovskii. Moscow, 2013; Ponomarev, A. L. Evolution of the Monetary Systems of the Black Sea Region and the Balkans in the 13th15th Centuries. Moscow, 2011. In these works we deal with scholarly discoveries at the crossroads of several disciplines.

Ключевые слова: история, медиевистика, историография, методология, контактная зона, мультикультурализм, Золотая Орда, М.Г. Крамаровский, квантитативная нумизматика, А.Л. Пономарев.

Key words: history, medieval studies, historiography, methodology, contact zone, multiculturalism, Golden Horde, M. G. Kramarovskii, quantitative numismatics, A. L. Ponomarev.

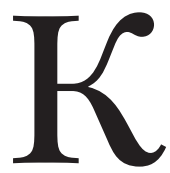

огда хулители современной отечественной науки говорят о ее малой продуктивности и отставании от «передового Запада», особенно в пресловутых индексах цитирования, мне кажется, что ответ на эти голословные обвинения коренится в малом знании обличителями реального состояния науки и траекторий научного поиска. Вот и сейчас я хочу привести несколько примеров того, где исследования самых последних лет сделали решительный бросок вперед, быть может, своим пониманием вопроса и научной методологией на несколько десятилетий опережая наше время и определяя вектор дальнейшего изучения.

Нельзя не заметить, что сейчас все больше и больше в науке укореняется мода не столько на то, чтобы найти истину, восстановить реалии прошлого («ах, этот надоевший призыв Л. фон Ранке «писать историю как она была»!) сколько на игру парадоксами, стремление найти любой ценой нестандартные подходы, приводить искусные, а чаще искусственные, сравнения отдаленного прошлого с современностью, способные поразить грантодателя или интересующегося историей дилетанта и обеспечить коммер- ческую (или иную) привлекательность проекта. Это не совсем строительство «потемкинских деревень», но что-то очень на него похожее. Успех обеспечен нестандартностью, и этот «побеждающий ключ успеха», на мой взгляд, опасен и ложен. Можно, к примеру, написать гениальное исследование по истории гончарного ремесла Причерноморья или Киликии и получить близкий к нулю индекс цитирования просто потому, что этими темами в мире занимается 5-6 человек. Здесь и сейчас. Пока не обнаружится значение этой темы для понимания какого-то важного экономического феномена, скрытого под слоем черепиц. Но разве менее такой автор заслуживает похвалы и высокой оценки чем, например, творцы парадоксов «новой хронологии», уже в силу скандальности имеющих высокий показатель (пусть и отрицательного, неважно) цитирования? Словом, благословенный и вожделенный отказ от догматизированной и вынужденно идеологизированной истории в России в 1990-е гг. привел не столько к искомому плюрализму мнений и снятию шор, сколько к подстраиванию под конъюнктуру рынка и взгляды чиновных работодателей. 


\section{Исторический журнал: научные исследования № 5 (17) • 2013}

\section{DOI: $10.7256 / 2222-1972.2013 .5 .9553$}

Но вернемся к вкладу в науку и к научному рецензированию (делу гораздо более важному, чем простой учет цитирования).

Много лет история Золотой Орды либо не изучалась вовсе, либо была далекой периферией ойкумены в глазах медиевиста, если только он не занимался историей миссионерства, работорговлей или путешествиями Марко Поло и Г. Рубрука. Экономика этого великого государства оставалась в тени, а своеобразная культура растворялась в определении «Восток».

Ведущий научный сотрудник Государственного Эрмитажа, доктор исторических наук Марк Григорьевич Крамаровский смог увидеть иные составляющие этого феномена. На это ушли многие годы труда археолога и искусствоведа, с 1978 г. руководившего экспедициями в Солхате (юго-восточный Крым) и осмысливавшего «восточные» коллекции и артефакты наших и западных музеев. Определенным шагом были организованные при его активном участии выставки ${ }^{1}$, но основные итоги трудов, рассеянных во многих, подчас труднодоступных публикациях, были подведены в только что изданной книге ${ }^{2}$.

Главное, что было сделано - это открытие огромной контактной зоны встречи цивилизаций, где со второй половины XIII в. в Улусе Джучи пролагаются пути трансконтинентальной торговли, опирающиеся на возрожденные города и на фактории итальянских купцов, торговые терминалы: Каффу (Феодосию), Тану (Азак, Азов), Хаджитархан (Астрахань), происходит унификация денежной системы и финансовых механизмов и т. д. Орда оказалась интегрирована в систему экономических связей Средиземноморья, с относительно координируемыми регуляторами цен и товаропотоков, действовавшими в XIII-XV вв., невзирая на многие частые и жестокие конфликты. Данные археологии, учтенные М.Г. Крамаровским, подтвердили сделанные ранее на основании документальных источников выводы ${ }^{3}$.

Многоязычие Золотой Орды, где арабский и персидский после принятия ислама со времени хана Узбека (1312-1341) стали языками ритуала и культуры, где на протяжении XIV в. официаль-

\footnotetext{
${ }^{1}$ Сокровища Золотой Орды. Каталог выставки. СПб., 2000; 3олотая Орда: история и культура. Казань, 23.08.2005-10.05.2006. Каталог. СПб., 2005.

${ }^{2}$ Крамаровский М.Г. Человек средневековой улицы. Золотая Орда. Византия. Италия. СПб., 2012.

${ }^{3}$ Карпов С.П. Итальянские морские республики и Южное Причерноморье в XIII-XV вв.: проблемы торговли. М.: МГУ, 1990.
}

ный монгольский язык вытеснялся литературным тюрки и где бытовали многие местные разновидности тюркского, где в отдельных анклавах и факториях говорили и писали на языках: славянском, греческом, латинском, еврейском, грабаре, не могло не порождать мультикультурализма, восприимчивости к достижениям (а иногда и недостаткам) иных культур. Были и факторы, консервирующие местную обособленность. К ним, например, относились поквартальная застройка многих золотоордынских городов на этно-конфессиональной основе, деятельность церковных приходов. Все это прекрасно показано М.Г. Крамаровским на примерах рукописей Дешт-и-Кыпчака, граффити изразцов, штукатурки и керамики, надгробий, надписей на оружии, золотых браслетах, чашах и поясах... Преобладавшая поначалу в официальном делопроизводстве уйгурица постепенно замещается арабицей. Важен сделанный автором вывод, что на улицах ордынских городов Крыма «конфессиональная принадлежность...нередко оказывается важнее этно-родовой аутентичности» (с. 71), при «отсутствии расовой или языковой сегрегации» (с. 73-74). Это подтверждается и сделанными мной ранее наблюдениями о существовании греко-русского прихода в Тане (Азаке) в XIV-XV вв. ${ }^{4}$

Улус Джучи рассматривается автором как особая цивилизационная модель в контексте ее взаимосвязей с Западом и Востоком. Поликультурализм Золотой Орды имел много аспектов. Он проявлялся и в работе армянских мастеровгончаров в Поволжье (с. 75-78), и в распространении сельджукской церемониальной посуды и предметов обихода в Крыму (с. 164-205), и в усвоении хорезмийской кашинной полихромной керамики золотоордынскими ремесленниками Поволжья (с. 79-92), и в использовании кыпчакско-куманской верхушкой церемониальных поясов, сделанных западноевропейскими (в основном итальянскими), а также сельджукскими мастерами (с. 93-105, 304-320), и в стеклянных изделиях типа Мурано, найденных (а вероятно, и изготовленных) в Крыму, скорее всего в Каффe (c. 325-331).

\footnotetext{
${ }^{4}$ Карпов С.П. Новые данные о православном приходе в Азове в XIV-XV вв.// Научно-богословские труды по проблемам православной миссии. Белгород, 1999. С. 21-25; он же. Межэтнические отношения и смешанные браки на окраине Латинской Романии (Тана, XIV-XV века) // Феномен идентичности в современном гуманитарном знании. К 70-летию академика B.A. Тишкова. М., 2011. С. 208-215; Karpov S. P. Greci e Latini in Tana Veneziana // I Greci Durante la venetocrazia: Uomini, spazio, idee (XIII-XVIII sec.). Atti del Convegno Internazionale di Studi. Venezia, 3-7 dicembre 2007. Venezia, 2009. P. 325-335.
} 


\section{Рецензии, библиография}

DOI: $10.7256 / 2222-1972.2013 .5 .9553$

Поликультурализм проявлялся и в характере расселения представителей различных конфессий на территории ордынских городов, где, как справедливо отмечает Крамаровский, используя пример Солхата, наблюдалась «этническая неоднородность населения; ...семантическая дискретность всех без исключения религиозных общин; ...открытость культуры для широкого спектра инноваций, как со стороны исламского, так и христианского Востока, Византии и Латинского мира» (с. 144-145).

Обо всем этом доказательно повествует книга Крамаровского. Не лишенная смелых и не всегда доказуемых гипотез, что и сам автор нередко признает, она вместе с тем показывает именно новые горизонты до сих мало изученной огромной лимитрофной зоны встречи цивилизаций. В частности, раскрывает феномен городской культуры, казалось бы «степной», кочевнической по началу, империи.

Одним из первых М.Г. Крамаровский обратился к анализу итальянских фресок Пизанелло и Амброджо Лоренцетти, изображавших «степняков» Золотой Орды. Ему удалось объяснить реалии изображений, их связь с предметами (кубками, сосудами), обнаруженными археологами в Северном Причерноморье, и показать причины интереса на Западе к этому, казалось бы, далекому и малоизвестному миру.

Разумеется, далеко не все построения М.Г. Крамаровского могут быть приняты без оговорок. Например, возражение вызывает высказанное им положение (с. 272) о том, что со второй половины XIII в. северный торговый путь в Причерноморье (через Крым и степи) первенствовал над южным (через Понтийские горы к Тавризу). Оба «рукава» черноморской торговли взаимно дополняли друг друга, и динамика этой коммерции была подвижной, зависела от меняющейся политической и экономической конъюнктуры. Это, например, четко прослеживается по маршрутам навигации венецианских галей «линии» с их основными терминалами - Трапезунд и Тана, и по индикатору сумм «инканти», отражавшему заинтересованность купцов во фрахте ${ }^{5}$. Распад державы Ильханов и «замятня» в Золотой орде были взаимосвязаны, порождая общий кризис,

\footnotetext{
${ }^{5}$ См.: Карпов С.П. Путями средневековых мореходов. Черноморская навигация Венецианской республики в XIII-XV вв. M., 1994; Karpov S.P. La Navigazione Veneziana nel Mar Nero XIII-XV sec. Ravenna, 2000; Stöckly D. Le Système de l'incanto des galées du marché de Venise (fin XIIIe - milieu XVe siècle). LeidenNY-Köln, 1995.
}

с большими усилиями преодолеваемый во второй половине XIV в.

Морское сражение 1352 г. под стенами Константинополя изображено далеко не только Петраркой (как на с. 274), но и в венецианской хронистике, например, в «Кодексе Морозини» ${ }^{6}$, в Хронике Дж. Карольдо ${ }^{7}$, пусть и менее художественно, но не менее точно.

Совершенно невероятным представляется высказанное автором давно отвергнутое современной историографией ${ }^{8}$ положение о присутствии и соперничестве венецианцев и генуэзцев в Причерноморье еще в 1160-1170-е гг. (с. 281).

Все эти частные возражения не затеняют главного: новых подходов к изучению прошлого на основании как письменных источников, так и памятников материальной культуры, новейших археологических открытий, в широком контексте аналогов отечественных и зарубежных музейных собраний. Не случайно к 70-летнему юбилею ученого его коллеги подготовили сборник, продолжающий и развивающий тему его научных штудий ${ }^{9}$.

Другим значительным научным открытием явилась книга ведущего научного сотрудника исторического факультета МГУ имени М.В. Ломоносова доктора исторических наук А.Л. Пономарева, посвященная денежным системам огромного региона Причерноморья и Балкан в XIII-XV вв. ${ }^{10}$ Большая и длительная работа автора по систематизации разнородного и разрозненного нумизматического материала в сопоставлении с данными письменных источников получила завершение. Благодаря тонкому использованию математических методов, достижений статистики, А.Л. Пономарев стал основоположником нового направления, которое можно определить как квантитативная нумизматика.

\footnotetext{
${ }^{6}$ Il Codice Morosini. Il mondo visto da Venezia (1094-1433). / Edizione critica, introduzione, indice e altri apparati di A. Nanetti. Spoleto, 2010. T. 1. P. 70-74.

${ }^{7}$ Caroldo Giovanni Giacomo. Istorii Venețiene. Vol. III. De la alegereadogelui Andrea Dandolo la moarteadogelui Giovanni Delfino (1343-1361) / Edițieîngrijită de Şerban V. Marin. Bucureşti, 2010. P. 55-58.

${ }^{8}$ См. обзор литературы и проблемы: Karpov S.P. Main changes in the Black Sea Trade and Navigation, $12^{\text {th }}-15^{\text {th }}$ Centuries // Proceedings of the $22^{\text {nd }}$ International Congress of Byzantine Studies. Sofia, 22-27 August 2011. Volume 1. Plenary Papers. Sofia, 2011. P. 417-420; Balard M. The Black Sea in the International Trade of the XIVth and XVth Centuries // ibid. P. 442-444.

${ }^{9}$ От Онона к Темзе. Чингисиды и их западные соседи. К 70-летию Марка Григорьевича Крамаровского. М., 2013.

${ }^{10}$ Пономарев А.Л. Эволюция денежных систем Причерноморья и Балкан в XIII-XV вв. М., 2011. 671 с.
} 


\section{Исторический журнал: научные исследования № 5 (17) • 2013}

\section{DOI: $10.7256 / 2222-1972.2013 .5 .9553$}

В моих разговорах с выдающимся специалистом по джучидской нумизматике Г.А. Федоровым-Давыдовым еще в 1980-х гг. Герман Алексеевич назвал труды молодого тогда ученого «нумизматикой будущего века».

В монографии Пономарева как исходные понятия рассматриваются системы денежных номиналов, денежного счета, весовые стандарты и проба, закономерности обращения, продуктивность работы монетных дворов. На основании полученных теоретических выводов анализируется денежное обращение Золотой Орды, Византии, Трапезундской империи, Балканских государств и Молдовы. Фоном для сравнения и сопоставлений, наряду с государством Ильханов и Улусом Джучи, избираются Венеция и Генуя, во многом своей денежной политикой определявшие денежное обращение и обменные курсы «валют» Восточного Средиземноморья. За всем этим стоят макроэкономические показатели, способные объяснить не только хозяйственное состояние того или другого государства, но и общие закономерности развития региона, включая и политическую составляющую, глубину и масштабность подъемов и кризисов.

А.Л. Пономарев сумел «расшифровать» непривычную для нас систему счета и записей средневековых монетчиков и финансистов, установить доныне неясные соотношения монет разных ареалов обращения, универсальные параметры денежных систем, объемы денеж- ных эмиссий. До него это не сделал никто ни в России, ни за рубежом. Он ответил на вопрос, за счет чего рынок благородных металлов рос и падал (с. 631), как происходила переоценка монеты, как и с какой скоростью она выбывала из обращения.

К числу несомненных находок автора отнесу его реконструкцию денежных реформ в Орде в XIV-XV вв., вывод из научного рассмотрения мифических «трахей» трапезундского императора Андроника Гида (с. 389-394), установление метрологических параметров чекана трапезундских аспров, пересмотр представлений о кризисе денежного обращения в Византии в середине XIV в., о судьбе и правильном названии серебряного перпера поздней Византии (его по недоразумению называют греческим именем неаполитанской монеты - ставрат) и многое другое. По всей книге разбросаны интереснейшие наблюдения над историей денежного обращения в регионе со всеми его перипетиями. Читателю лишь остро недостает сводных таблиц соотношения курсов разных монет между собой на протяжении рассматриваемой эпохи, и это затрудняет «прагматическое», а не только теоретико-методологическое использование книги.

В целом же мы имеем место с научными открытиями на стыке нескольких дисциплин, и әто я и хочу показать критикам мнимого застоя в нашей историографии.

\section{Библиографбия:}

1. Balard M. The Black Sea in the International Trade of the XIVth and XVth Centuries // Proceedings of the 22nd International Congress of Byzantine Studies. Sofia, 22-27 August 2011. Volume 1. Plenary Papers. Sofia, 2011. P. 442-444.

2. Caroldo Giovanni Giacomo. Istorii Veneţiene. Vol. III. De la alegereadogelui Andrea Dandolo la moarteadogelui Giovanni Delfino (1343-1361) / Ediţiê̂ngrijită de Șerban V. Marin. Bucureşti, 2010. P. 55-58.

3. Il Codice Morosini. Il mondo visto da Venezia (1094-1433). / Edizione critica, introduzione, indice e altri apparati di A. Nanetti. Spoleto, 2010. T. 1. P. 70-74.

4. Karpov S. P. Greci e Latini in Tana Veneziana // I Greci Durante la venetocrazia: Uomini, spazio, idee (XIII-XVIII sec.). Atti del Convegno Internazionale di Studi. Venezia, 3-7 dicembre 2007. Venezia, 2009. P. 325-335.

5. Karpov S.P. La Navigazione Veneziana nel Mar Nero XIII-XV sec. Ravenna, 2000.

6. Karpov S.P. Main changes in the Black Sea Trade and Navigation, 12th-15th Centuries // Proceedings of the 22nd International Congress of Byzantine Studies. Sofia, 22-27 August 2011. Volume 1. Plenary Papers. Sofia, 2011. P. 417-420.

7. Stöckly D. Le Système de l'incanto des galées du marché de Venise (fin XIIIe - milieu XVe siècle). Leiden- NY-Köln, 1995.

8. Карпов С.П. Итальянские морские республики и Южное Причерноморье в XIII-XV вв.: проблемы торговли. М.: МГУ,1990.

9. Карпов С.П. Межэтнические отношения и смешанные браки на окраине Латинской Романии (Тaна, XIV-XV века) // Феномен идентичности в современном гуманитарном знании. К 70-летию академика В.А. Тишкова. М., 2011. С. 208-215.

10. Карпов С.П. Новые данные о православном приходе в Азове в XIV-XV вв. // Научно-богословские труды по проблемам православной миссии. Белгород, 1999. С. 21-25.

11. Карпов С.П. Путями средневековых мореходов. Черноморская навигация Венецианской республики в XIII-XV вв. M.,1994.

12. Крамаровский М.Г. Человек средневековой улицы. Золотая Орда. Византия. Италия. СПб., 2012. 


\section{Рецензии, библиография}

DOI: $10.7256 / 2222-1972.2013 .5 .9553$

13. От Онона к Темзе. Чингисиды и их западные соседи. К 70-летию Марка Григорьевича Крамаровского. М., 2013.

14. Пономарев А.Л. Эволюция денежных систем Причерноморья и Балкан в XIII-XV вв. M., 2011. 671 с.

15. Сокровища Золотой Орды. Каталог выставки. СПб., 2000; Золотая Орда: история и культура. Казань, 23.08.200510.05.2006. Каталог. СПб., 2005.

\section{References:}

1. Balard M. The Black Sea in the International Trade of the XIVth and XVth Centuries // Proceedings of the 22nd International Congress of Byzantine Studies. Sofia, 22-27 August 2011. Volume 1. Plenary Papers. Sofia, 2011. P. 442-444.

2. Caroldo Giovanni Giacomo. Istorii Veneţiene. Vol. III. De la alegereadogelui Andrea Dandolo la moarteadogelui Giovanni Delfino (1343-1361) / Ediţieîngrijită de Şerban V. Marin. București, 2010. P. 55-58.

3. Il Codice Morosini. Il mondo visto da Venezia (1094-1433). / Edizione critica, introduzione, indice e altri apparati di A. Nanetti. Spoleto, 2010. T. 1. R. 70-74.

4. Karpov S. P. Greci e Latini in Tana Veneziana // I Greci Durante la venetocrazia: Uomini, spazio, idee (XIII-XVIII sec.). Atti del Convegno Internazionale di Studi. Venezia, 3-7 dicembre 2007. Venezia, 2009. P. 325-335.

5. Karpov S.P. La Navigazione Veneziana nel Mar Nero XIII-XV sec. Ravenna, 2000.

6. Karpov S.P. Main changes in the Black Sea Trade and Navigation, 12th-15th Centuries // Proceedings of the 22nd International Congress of Byzantine Studies. Sofia, 22-27 August 2011. Volume 1. Plenary Papers. Sofia, 2011. P. 417-420.

7. Stöckly D. Le Système de l'incanto des galées du marché de Venise (fin XIIIe - milieu XVe siècle). Leiden-NY-Köln, 1995.

8. Karpov S.P. Ital'yanskie morskie pespubliki i Yuzhnoe Prichernomor'e v XIII-XV vv.: problemy torgovli. M.: MGU,1990.

9. Karpov S.P. Mezhetnicheskie otnosheniya i smeshannye braki na okraine Latinskoi Romanii (Tana, XIV-XV veka) // Fenomen identichnosti v sovremennom gumanitarnom znanii. K 70-letiyu akademika V.A. Tishkova. M., 2011. S. 208-215.

10. Karpov S.P. Novye dannye o pravoslavnom prikhode v Azove v XIV-XV vv. // Nauchno-bogoslovskie trudy po problemam pravoslavnoi missii. Belgorod, 1999. S. 21-25.

11. Karpov S.P. Putyami srednevekovykh morekhodov. Chernomorskaya navigatsiya Venetsianskoi respubliki v XIII-XV vv. M.,1994.

12. Kramarovskii M.G. Chelovek srednevekovoi ulitsy. Zolotaya Orda. Vizantiya. Italiya. SPb., 2012.

13. Ot Onona k Temze. Chingisidy i ikh zapadnye sosedi. K 70-letiyu Marka Grigor'evicha Kramarovskogo. M., 2013.

14. Ponomarev A.L. Evolyutsiya denezhnykh sistem Prichernomor'ya i Balkan v XIII-XV vv. M., 2011. 671 s.

15. Sokrovishcha Zolotoi Ordy. Katalog vystavki. SPb., 2000; Zolotaya Orda: istoriya i kul'tura. Kazan', 23.08.2005-10.05.2006. Katalog. SPb., 2005. 